\title{
Ensino de habilidades rítmicas para meninos com Transtorno do Espectro do Autismo
}

\author{
Teaching rhythmic skills for boys with Autism Spectrum Disorder
}

Enseñanza de habilidades rítmicas para niños con Trastorno del Espectro del Autismo

\section{* Valéria Peres Asnis}

Doutora pela Universidade Federal de São Carlos, São Carlos, São Paulo, Brasil. valeria.asnis@gmail.com

\section{** Ana Arantes}

Professora doutora pela Universidade Federal de São Carlos, São Carlos, São Paulo, Brasil. ana.arantes@gmail.com

\section{${ }^{* * *}$ Nassim Chamel Elias}

Professor doutor pela Universidade Federal de São Carlos, São Carlos, São Paulo, Brasil. nchamel@terra.com.br - http://orcid.org/0000-0003-4197-623X

Recebido em 23 de agosto de 2018

Aprovado em 05 de novembro de 2018

Publicado em 06 de maio de 2019

\section{RESUMO}

Crianças são diagnosticadas com Transtorno do Espectro do Autismo (TEA) quando apresentam déficits na comunicação e interação sociais e comportamentos e interesses restritos e repetitivos. Estudos afirmam que usar estratégias adequadas para o ensino de música para pessoas com TEA pode colaborar para um ambiente propício à aprendizagem musical, desenvolvimento de comportamentos sociais adequados e diminuições de comportamentos inadequados. Este trabalho teve como objetivo verificar os efeitos do uso de reforçamento diferencial e esvanecimento de dicas no aprendizado de habilidades rítmicas ao tocar instrumentos musicais na presença de cantigas de roda com quatro meninos com idades entre oito e 12 anos diagnosticados com TEA e se o engajamento nas atividades musicais levaria à redução de comportamentos inadequados e aumento de comportamentos adequados. Foi utilizado um delineamento de linha de base múltipla entre repertórios musicais, em que o participante foi ensinado a tocar um instrumento musical acompanhando um ritmo pré-estabelecido. Os resultados indicam que todos os participantes aprenderam a resposta ao pulso musical e generalizaram para todas as cantigas deste estudo. Este estudo corroborou outros estudos que indicam a efetividade de atividades musicais como ferramenta para desenvolver e ampliar comportamentos adequados e diminuir aqueles socialmente inadequados 
Palavras-chave: Análise do Comportamento Aplicada; Transtorno do Espectro do Autismo; Música.

\section{ABSTRACT}

Children are diagnosed with Autism Spectrum Disorder (ASD) when they present deficits in social communication and interaction and restricted and repetitive behaviors and interests. Studies suggest that using appropriate strategies for teaching music to people with ASD can contribute to an environment conducive to musical learning, developing appropriate social behaviors, and diminishing inappropriate behaviors. This study aimed to verify the effects of the use of differential reinforcement and prompt fading in the learning of rhythmic skills when playing musical instruments in the presence of popular Brazilian songs with four eight-to-12year-old boys diagnosed with ASD and if the engagement in the musical activities would lead to the reduction of inappropriate behaviors and increase of appropriate behaviors. A multiple baseline design across musical repertoires was used, in which the participant was taught to play a musical instrument at a pre-established rhythm. The results indicate that all participants learned the response to the musical pulse and generalized to all songs in this study. This study corroborated other studies that indicate the effectiveness of musical activities as a tool to develop and expand appropriate behaviors and diminish those that are socially inadequate.

Keywords: Applied Behavior Analysis; Autism Spectrum Disorder; Music.

\section{RESUMEN}

Los niños son diagnosticados con trastorno del espectro del autismo (TEA) cuando presentan déficits en la comunicación e interacción social y comportamientos e intereses restringidos y repetitivos. Los estudios afirman que utilizar estrategias adecuadas para la enseñanza de música para personas con TEA puede colaborar para un ambiente propicio para el aprendizaje musical, el desarrollo de comportamientos sociales adecuados y disminuciones de comportamientos inadecuados. Este trabajo tuvo como objetivo verificar los efectos del uso de reforzamiento diferencial y el desvanecimiento de consejos en el aprendizaje de habilidades rítmicas al tocar instrumentos musicales en presencia de cantigas de rueda con cuatro niños con edades entre ocho y 12 años diagnosticados con TEA y si el compromiso en las actividades musicales llevaría a la reducción de comportamientos inadecuados y el aumento de comportamientos adecuados. Se utilizó un delineamiento de línea de base múltiple entre repertorios musicales, en que el participante fue enseñado a tocar un instrumento musical acompañando un ritmo preestablecido. Los resultados indican que todos los participantes aprendieron la respuesta al pulso musical y generalizaron para todas las canciones de este estudio. Este estudio corroboró otros estudios que indican la efectividad de actividades musicales como herramienta para desarrollar y ampliar comportamientos adecuados y disminuir aquellos socialmente inadecuados. 
Palabras clave: Análisis del Comportamiento Aplicado; Trastorno del Espectro del Autismo; Música.

\section{Introdução}

O diagnóstico do Transtorno do Espectro do Autismo (TEA) tem sido alterado ao longo dos anos e, atualmente, de acordo com a quinta versão do Manual de Diagnóstico e Estatística dos Transtornos Mentais (DSM-5; APA, 2014), para que uma pessoa seja diagnosticada com esse transtorno precisa apresentar (i) déficits persistentes na comunicação e na interação social e (ii) padrões restritos e repetitivos de comportamento, interesses ou atividades, em diversos contextos. Segundo os critérios diagnósticos para o TEA, indivíduos dentro do espectro podem apresentar sensibilidade alterada a estímulos do ambiente, incluindo os estímulos sonoros, e responder de forma incomum ou inadequada a essas estimulações. Por exemplo, Gallastegi (2005) indicou que participantes com TEA, quando comparados com participantes com síndrome de Down ou deficiência intelectual, apresentaram a média mais baixa em habilidades perceptivas auditivas, o que pode dificultar o aprendizado de habilidades musicais.

As habilidades musicais envolvem percepção e discriminação auditiva pela prática instrumental repetitiva de tarefas sensoriais e motoras simultâneas, como tocar piano ou um instrumento de percussão. Algumas pesquisas têm fornecido evidências de que 0 treinamento musical modifica as regiões cerebrais correspondentes, tanto no nível funcional quanto no estrutural (BAILEY; ZATORRE; PENHUNE, 2014; KLEBER et al., 2010; STEELE et al., 2013). Atividades de musicalização também podem ser um meio significativo para aprimorar as diferentes formas de comunicação de pessoas com atraso no desenvolvimento (LOURO, 2006), servindo de estímulo para o controle de movimentos específicos, colaborando para atividades em grupo e favorecendo a comunicação. De acordo com Srinivasan e Bhat (2013), o treino musical impacta positivamente no desenvolvimento da comunicação, da interação social e de aspectos emocionais e motores em crianças com autismo e outros atrasos de desenvolvimento.

Segundo Martin (2013), profissionais da música poderiam utilizar intervenções comportamentais em suas sessões com alunos com TEA, incluindo estratégias adequadas para o ensino e adaptações que atendam às suas necessidades específicas, o que poderia gerar um ambiente propício à aprendizagem musical e o desenvolvimento de comportamentos sociais adequados e possíveis diminuições de comportamentos inadequados. Entretanto, os estudos da área comportamental ainda estão restritos ao uso 
http://dx.doi.org/10.5902/1984686X34415

da música como consequência para respostas adequadas. Lanovaz, Sladeczek e Rapp (2011), Lanovaz, Rapp e Ferguson (2012) e Saylor, Sidener, Reeve, Fetherston e Progar (2012), por exemplo, reportaram redução de estereotipia vocal em crianças com autismo quando introduziram acesso não-contingente a música. Silva e Elias (2017) utilizaram música como consequência para o ensino de respostas de ouvinte para relações espaciais de direita-esquerda envolvendo partes do corpo a cinco participantes com autismo e dois com deficiência intelectual, obtendo resultados positivos na aprendizagem das habilidades ensinadas.

Para o ensino de música para as crianças que se encontram dentro do espectro do autismo é necessário considerar alguns pontos importantes como a comunicação entre o educador musical e seu aluno com TEA e a adaptação de atividades musicais de acordo com as características do aluno. Segundo Hammel e Hourigan (2013, p. 84), o "objetivo fundamental dessas mudanças nos planos de aula diários é aumentar a ocorrência de comportamentos apropriados, diminuir a ocorrência de comportamento negativo e ensinar um comportamento apropriado que esteja ausente no repertório desses estudantes", o que vai melhorar o ambiente e favorecer o aprendizado musical.

Considerando os benefícios que podem derivar do aprendizado de habilidades musicais, esta pesquisa teve como objetivo verificar os efeitos do uso de reforçamento diferencial e esvanecimento de dicas no aprendizado de habilidades rítmicas ao tocar instrumentos musicais na presença de cantigas de roda com quatro meninos com idades entre oito e 12 anos diagnosticados com TEA e que frequentavam instituição especializada. Adicionalmente, foi verificado se o engajamento nas tarefas com atividades musicais levaria à redução da frequência de comportamentos inadequados e aumento de comportamentos adequados.

Reforçamento diferencial implica em reforçar determinadas respostas de uma classe que atendam a um critério específico ao longo de alguma dimensão (frequência, topografia, duração, latência ou magnitude) e deixar de reforçar todas as outras respostas na classe (extinção). Dicas são estímulos antecedentes suplementares usados para ocasionar uma resposta correta na presença de um estímulo discriminativo que acabará por controlar o comportamento. Esvanecimento refere-se ao procedimento utilizado para transferir o controle da resposta de um estímulo (dica) para outro (estímulo discriminativo), em que os estímulos podem ser gradualmente introduzidos ou gradualmente removidos (COOPER; HERON; HEWARD, 2007; MARTIN; PEAR, 2009). 


\section{Método}

\section{Participantes}

O estudo teve a participação de quatro meninos (P1, P2, P3 e P4) diagnosticados com TEA. Para participar da pesquisa, a criança deveria ter diagnóstico de TEA, sem impossibilidades motoras para o manejo de instrumentos musicais e que nunca tivesse tido aulas formais de música antes do início da pesquisa. Para o recrutamento dos participantes, foi realizada uma reunião com a coordenadora e a psicóloga da instituição especializada em que os participantes estavam matriculados, para apresentar e esclarecer os objetivos e procedimentos da pesquisa, devidamente aprovada pelo Comitê de Ética em Pesquisa em Seres Humanos da Universidade Federal de São Carlos (Parecer no 829.680). Após a indicação dos participantes, o Termo de Consentimento Livre e Esclarecido (TCLE) foi encaminhado aos pais e/ou responsáveis, para obtenção das devidas assinaturas. $\mathrm{O}$ Comitê de Ética permitiu dispensa da assinatura do Termo de Assentimento Livre e Esclarecido pelos participantes. A coleta de dados iniciou somente após assinatura do TCLE.

P1 tinha oito anos, com diagnóstico F-84 (autismo infantil) de acordo com classificação do CID-10 (Classificação Internacional de Doenças; Organização Mundial de Saúde [OMS], 1993) e autismo moderado (pontuação 32) pelo CARS (Childhood Autism Rating Scale; SCHOPLER; REICHLER; RENNER, 1988). Ele emitia respostas de imitação em algumas ocasiões, evitava contato visual, necessitava de repetição para prestar atenção, apresentava ecolalia moderada e não compreendia a comunicação não verbal dos outros. P2 tinha nove anos, com diagnóstico F-84 de acordo com o CID-10 e autismo moderado pelo CARS (pontuação 36,5). P2 tinha dificuldade em imitar movimentos complexos, fazia contato visual curto, apresentava episódios de autolesão, pouca fala espontânea e fala fora de contexto, riso e choro sem motivo aparente e dificuldade em ficar sentado. P3 tinha nove anos, com diagnóstico F-84 de acordo com o CID-10, mas ele não foi submetido a nenhuma avaliação padronizada. Ele não mantinha contato visual, mas seguia instruções, falava algumas palavras e apresentava episódios de grito. P4 tinha 12 anos, com diagnóstico F84 de acordo com o CID-10 e se encontrava no Nível C da Escala de Maturidade Mental Colúmbia (ALVES; DUARTE, 2001), ou seja, o participante apresentava um nível de maturidade mental condizente com o QI de uma criança típica de seis a seis anos e meio de idade. P4 tapava os ouvidos para alguns sons, evitava contato visual e resistia a contato 
físico, respondia a comunicação verbal de outros, falava fora de contexto, apresentava riso ou choro sem motivo aparente, tinha boa memória visual, mas déficits na gesticulação e na coordenação motora. Esses dados foram obtidos a partir dos protocolos médicos e consulta à equipe técnica da Instituição em que os participantes estavam matriculados.

\section{Local e Materiais}

A pesquisa foi realizada na copa/cozinha do setor de autismo da instituição especializada em que os participantes estavam matriculados. No local havia uma geladeira, um micro-ondas, dois armários, duas mesas com oito cadeiras, uma mesa pequena com um filtro de água, uma lixeira e um quadro de parede para anexar avisos. Foram utilizados um chocalho, um guizo, um par de clavas e um aparelho de som (para tocar as cantigas de roda). Duas cadeiras foram utilizadas nas sessões de intervenção e de teste. Todas as sessões foram vídeo-gravadas com uma câmera da marca Sony - Cyber-shot que ficava posicionada em cima de uma mesa de forma a captar uma imagem focada no participante juntamente com a pesquisadora.

\section{Instrumentos}

Foram elaborados três protocolos para registrar as respostas dos participantes bem como os comportamentos apresentados em cada sessão:

1. Tempo de permanência na atividade. Após iniciada a cantiga, assim que o participante emitia respostas de tocar o instrumento da forma estabelecida como correta pela pesquisadora, iniciava-se a contagem do tempo; a contagem era interrompida caso o participante tocasse 0 instrumento de outra forma e era reiniciada assim que ele se engajava novamente na forma correta de tocar o instrumento. $\mathrm{O}$ comportamento esperado para cada instrumento em cada cantiga está definido no item "Procedimentos Experimentais".

2. Comportamentos adequados. Neste protocolo foram registrados os comportamentos considerados socialmente adequados funcionalmente definidos da seguinte forma:

- Seguir comando: Quando a pesquisadora dava alguma instrução vocal (exp.: sente-se, pegue o instrumento musical, etc.), o participante respondia de acordo com a instrução em até $5 \mathrm{~s}$; 
http://dx.doi.org/10.5902/1984686X34415

- Responder sob controle temático (intraverbal): Quando a pesquisadora perguntava algo ou iniciava algum diálogo e o participante respondia de acordo com a pergunta ou falava alguma palavra dentro do contexto da conversa iniciada pela pesquisadora em até $5 \mathrm{~s}$;

- Aceitar ajuda: Quando o participante permitia que a pesquisadora mantivesse a mão encostada em seu braço ou mão por pelo menos $50 \%$ do período total de cada cantiga;

- Atentar: Quando o participante direcionava o olhar para a pesquisadora ou materiais após instrução fornecida pela pesquisadora;

- Cumprimentar e/ou despedir-se: Quando o participante realizava algum sinal ou emitia uma fala de cumprimento ao entrar na sala de coleta e/ou despedida ao final da sessão de ensino (exp.: falar oi, fazer sinal de tchau, falar tchau, abraçar a pesquisadora).

3. Comportamentos inadequados. Neste protocolo foram registrados os comportamentos considerados socialmente inadequados funcionalmente definidos da seguinte forma:

- Desobedecer a comandos: Quando a pesquisadora dava alguma instrução verbal vocal (exp.: sente-se, pegue o instrumento musical, etc.), o participante emitia respostas que não correspondiam à instrução;

- Recusar ajuda: Quando o participante não permitia que a pesquisadora mantivesse a mão encostada em seu braço ou mão por pelo menos $50 \%$ do período total de cada cantiga;

- Fugir da atividade: Quando, após instrução ou iniciada uma tentativa, o participante levantava-se da cadeira em que estava realizando as atividades para olhar pela janela ou ir em direção da porta. Interromper as atividades e se dirigir em direção à janela, interruptor ou quadro de informações existentes na sala de coleta de dados, ou virar o corpo para trás no meio das tentativas de ensino;

- Chorar: Quando caíam lágrimas dos olhos do participante ao mesmo tempo em que chamava pela mãe ou pelo pai. 


\section{Avaliação Indireta de Itens de Preferência}

Para a seleção de itens de preferência a serem utilizados como consequências para as respostas corretas em tentativas de ensino, foram consultadas a psicóloga e a coordenadora da Instituição. Para P1, foram indicados a pipoca e chocolates M\&M®. Para P2 foi indicada a pipoca, mas no decorrer da pesquisa, a pipoca perdeu seu valor reforçador, sendo substituída por uma cama elástica de pular; porém, a cama logo perdeu seu valor reforçador, optando-se em voltar a usar a pipoca. Para P3 foram indicados a pipoca e chocolates $M \& M \circledast$. Para P4 foi indicada a bala de amendoim. Para todos os participantes, no decorrer da pesquisa, os itens indicados inicialmente foram pareados e, quando possível, gradualmente substituídos por consequências sociais (abraços e elogios).

\section{Estímulos Experimentais}

Foram selecionadas, inicialmente três cantigas e três instrumentos musicais (ver Figura 1). A cantiga "Carneirinho, carneirão" foi introduzida para P4, pois, na presença da cantiga "Capelinha de Melão", o participante apresentou comportamentos incompatíveis com a atividade, como tampar os ouvidos e recusar-se a realizá-la. Para a escolha da cantiga "Carneirinho, carneirão" o pai do participante indicou esta cantiga como uma das preferidas pelo filho. A seguir são apresentadas as cantigas e o comportamento esperado para cada uma. As quatro cantigas de roda selecionadas para esta pesquisa foram retiradas do livro de Pimentel (2002). Segundo Ilari (2002, p. 84), este tipo de cantiga possui "intervalos melódicos pequenos, ritmos bastante simples e uma quantidade grande de repetições de frases musicais", sendo, portanto, ideal para trabalhar com os participantes deste estudo.

Figura 1 - Foto dos instrumentos utilizados no estudo, da esquerda para a direita: chocalho, guizo e par de clavas

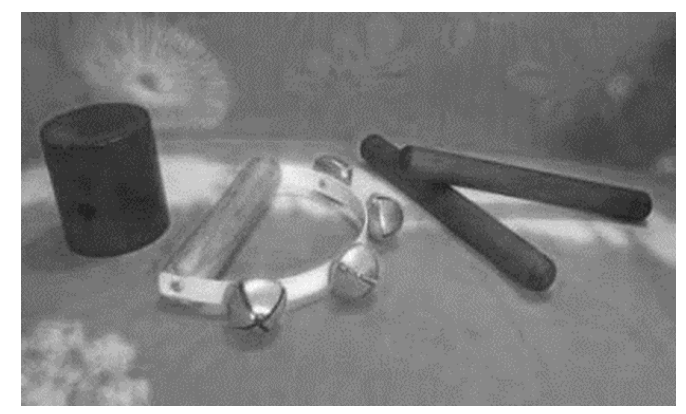

Fonte: Fonte própria.

Repertório 1 - Meu limão, meu limoeiro. Para esta cantiga, com duração de 36s, foi selecionado o instrumento musical "chocalho". A cantiga possui um compasso quaternário 
(4/4 - leia-se quatro por quatro) e o participante deveria tocar o chocalho no pulso da cantiga (Figura 2). Ao ouvir o início da cantiga, o participante deveria realizar movimentos verticais (de cima para baixo e vice-versa) com o chocalho, de forma contínua, a cada 48 décimos de segundos, aproximadamente, até o final da cantiga. Respostas corretas foram seguidas de acesso ou consumo do item de preferência.

Figura 2 - Representação de um compasso escrito em tempo quaternário. O participante deveria tocar o instrumento musical em cada semínima



Fonte: Fonte própria.

Repertório 2 - Sereno. Para esta cantiga, com duração de 40s, foi selecionado o instrumento musical "guizo". O participante deveria tocar o guizo toda vez que a palavra "sereno" fosse pronunciada. Portanto, os participantes deveriam tocar o guizo por quatro vezes nesta cantiga, que tem a seguinte letra: "Sereno, eu caio eu caio! / Sereno, deixai cair! / Sereno da madrugada não deixou meu bem dormir. / Sereno da madrugada não deixou meu bem dormir".

$\mathrm{Na}$ presença de quatro estímulos distintos da cantiga (cada um deveria funcionar como estímulo discriminativo para o início de uma resposta) o participante deveria agitar o guizo, enquanto a palavra "sereno" fosse emitida. Os estímulos que sinalizavam o início de cada resposta foram, na seguinte sequência: (i) a primeira vez em que a palavra "sereno" é cantada, logo no início da cantiga, em que há somente a presença de uma melodia sendo tocada por instrumentos musicais, aproximadamente aos nove segundos; (ii) após ouvir a segunda palavra "caio" na primeira estrofe, aproximadamente aos quatorze segundos; (iii) após ouvir a palavra "cair" na segunda estrofe, aproximadamente aos dezoito segundos; (iv) após ouvir a palavra "dormir" na quarta estrofe, aproximadamente aos vinte e sete segundos. Resposta corretas foram seguidas de acesso ou consumo do item de preferência.

Repertório 3 - Capelinha de Melão (para P1, P2 e P3). Para esta cantiga, com duração de 40s, foi selecionado o instrumento musical "clavas". A cantiga possui um compasso binário (2/4 - leia-se dois por quatro) e o participante deveria tocar as clavas na subdivisão do tempo (Figura 3). Ao ouvir o início da cantiga, o participante deveria bater uma clava 


$$
\text { http://dx.doi.org/10.5902/1984686X34415 }
$$

perpendicularmente à outra, de forma contínua, a cada 36 décimos de segundos, aproximadamente. Respostas corretas foram seguidas de acesso ou consumo do item de preferência.

Figura 3 - Representação de um compasso binário. As figuras musicais escritas na parte de cima da linha preta mostram os tempos do compasso binário ou o pulso musical e as figuras musicais escritas abaixo da linha preta indicam a subdivisão de cada tempo/pulso musical que deveria ser tocada pelos participantes

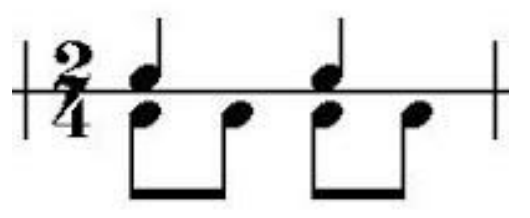

Fonte: Fonte própria.

Repertório 3 - Carneirinho, carneirão (para P4). Para esta cantiga, com duração de 35s, foi selecionado o instrumento musical "clavas". A cantiga possui um compasso binário (2/4) e o participante deveria tocar as clavas na subdivisão da melodia, como representada na Figura 4. Ao ouvir o início da cantiga, o participante deveria bater uma clava perpendicularmente à outra, de forma contínua, a cada 21 décimos de segundos, aproximadamente. Respostas corretas foram seguidas de acesso ou consumo ao item de preferência.

\section{Delineamento Experimental}

Foi utilizado um delineamento de linha de base múltipla (COZBY, 2014) entre repertórios musicais, composto por três pares "cantiga de roda/instrumento musical". Assim que o participante alcançou o critério de aprendizagem para o primeiro par, foi realizada sonda para os três pares; ao término do ensino do segundo par, foi realizada nova sonda.

\section{Procedimento experimental}

Linha de Base: Na Linha de Base, para cada par instrumento/cantiga de roda, a pesquisadora entregou o instrumento musical ao participante, colocou o CD com a cantiga de roda designada para o instrumento no aparelho de som e iniciou sua execução, sem dar nenhuma instrução prévia, e observou se a resposta selecionada para tocar o instrumento ocorreu. Foram feitas três tentativas para cada cantiga, no mesmo dia, em momentos diferentes. A ocorrência dos comportamentos adequados e inadequados do participante desde sua chegada à sala de coletas de dados até o final da sessão foram registrados. 
http://dx.doi.org/10.5902/1984686X34415

Ensino: Em cada sessão de ensino, a cantiga a ser ensinada foi apresentada quatro vezes. Foram utilizadas dicas de imitação e ajuda física total e parcial, com retirada gradual assim que o participante apresentava respostas consistentes consecutivas. Ao iniciar o ensino de uma cantiga, em cada tentativa, participante e pesquisadora manipulavam o mesmo tipo de instrumento musical, sendo um para o participante e um para a pesquisadora. Assim que a pesquisadora apertava o botão de tocar no aparelho de som, dando início à cantiga, a pesquisadora fornecia a instrução "Toque o <nome do instrumento>" (por exemplo, "Toque o chocalho"), enquanto fazia o movimento de pegar e tocar o instrumento conforme procedimento descrito no item "Estímulos Experimentais", para que o participante imitasse a ação sendo realizada. Caso o participante não imitasse a ação, na tentativa seguinte, a pesquisadora fornecia ajuda física. Para a ajuda física total do chocalho, a pesquisadora mantinha sua mão na mão em que o participante estava segurando o instrumento e realizava movimentos verticais (de cima para baixo e vice-versa) de forma contínua até o final da cantiga. Para o guizo, a pesquisadora mantinha sua mão na mão em que o participante estava segurando o instrumento e o agitava, enquanto a palavra "sereno" era emitida. Para as clavas, a pesquisadora mantinha suas mãos nas mãos do participante segurando o instrumento e batia uma clava perpendicularmente à outra, de forma contínua, até o término da cantiga. A retirada gradual se deu pela magnitude da força aplicada ao segurar as mãos do participante. Respostas corretas, com ou sem ajuda, foram seguidas da entrega de itens de preferência. O critério de aprendizagem para cada par foi de três respostas corretas, para a cantiga inteira, independentes (sem ajuda) e consecutivas.

Sondas: As sondas ocorreram no dia de coleta imediatamente após o participante alcançar critério de aprendizagem para um par instrumento/cantiga de roda. Cada sonda iniciava com o participante sentado em frente à pesquisadora, com um dos instrumentos à sua frente. Ao iniciar uma cantiga (por exemplo, "Meu limão, meu limoeiro"), a pesquisadora forneceu a instrução "Toque o <nome do instrumento>" (por exemplo, "Toque o chocalho"). Ao final de cada cantiga, o instrumento era retirado e iniciava a próxima tentativa, como novo par. Era feita uma sonda para cada par.

Generalização: Após o participante alcançar critério de aprendizagem para os três pares, foi aplicada uma sonda com a recombinação entre as cantigas e os instrumentos selecionados, de modo que o participante tocasse um dos instrumentos musicais para uma das cantigas que não aquela ensinada para tal instrumento, a partir da instrução verbal 
fornecida pela pesquisadora. As recombinações foram: chocalho com Sereno e com Capelinha de Melão; guizo com Meu limão, meu limoeiro e Capelinha de Melão; as clavas com Meu limão, meu limoeiro e Sereno. O procedimento foi semelhante ao aplicado nas sondas.

\section{Resultados}

A Figura 4 apresenta os desempenhos de P1, P2, P3 e P4 nas sessões de linha de base, ensino, manutenção e generalização em relação aos comportamentos-alvo. No Eixo Y é apresentada a porcentagem de tempo total em que o participante emitiu respostas corretas em relação ao tempo total da sessão para cada par instrumento/cantiga.

Os dados de linha de base indicam que nenhum participante apresentava os comportamentos-alvo antes do ensino. De maneira geral, após o ensino, todos os participantes alcançaram critério para os pares "Meu limão meu limoeiro/chocalho" e "Capelinha de melão ou Carneirinho carneirão/clavas" (primeiro e terceiro gráficos de cada participante na Figura 4). Para essas cantigas, apesar dos instrumentos e, portanto, as ações motoras serem distintos, os participantes deveriam tocar os instrumentos de forma contínua, de acordo com pulso ou subdivisão da cantiga. Os dados de manutenção para esses pares indicam que os participantes continuaram a emitir essas respostas ao longo de todo procedimento. Para o par "Sereno/guizo" (segundo gráfico de cada participante na Figura 4), os desempenhos foram distintos, sendo que somente P1 e P3 alcançaram o critério de aprendizagem e mantiveram essas respostas ao longo do procedimento. Para essa cantiga, diferentemente das outras duas, os participantes deveriam discriminar a passagem do tempo ou a presença de determinadas palavras que deveriam evocar a resposta definida como correta, ao invés de tocar o instrumento de forma contínua, segundo pulso ou subdivisão.

Figura 4 - Desempenhos de P1, P2, P3 e P4 nas sessões de linha de base, ensino, manutenção e generalização em relação às habilidades musicais. Os círculos pretos representam o desempenho musical do participante ao longo das sessões. os triângulos cheios representam dados de manutenção e os círculos brancos representam dados de generalização (novos pares instrumento/cantiga). As linhas pontilhadas indicam a introdução da fase de ensino e representam o delineamento de linha de base múltipla entre repertórios musicais 



Revista Educação Especial | v. 32 | 2019 - Santa Maria

Disponível em: https://periodicos.ufsm.br/educacaoespecial 
Fonte: Fonte própria.

Os dados também indicam que houve generalização parcial das respostas aprendidas em um determinado par para outros pares não ensinados diretamente. No caso da cantiga "Sereno", esperava-se que os participantes tocassem os instrumentos musicais "chocalho" e "clavas" toda vez em que a palavra "Sereno" fosse pronunciada, porém, o que se verificou é que todos os participantes ficaram sob controle das respostas aprendidas anteriormente de tocar os outros instrumentos de maneira contínua, portanto, a generalização se deu em função do instrumento e não da cantiga.

A Tabela 1 mostra a média de ocorrência dos comportamentos adequados e inadequados nas sessões de linha de base e de ensino para cada par instrumento/cantiga. Conforme descrito no método, foram registrados seis comportamentos adequados e seis inadequados, sendo que foi registrada somente se determinado comportamento ocorreu durante a sessão, independentemente do número de vezes. Os dados da Tabela 1 indicam que, para todos os participantes, a média de comportamentos adequados aumentou e a de inadequados diminuiu das sessões de linha de base para as sessões de ensino, em que os itens de preferência eram apresentados como consequências para respostas corretas, ocasionando maior interação entre participante e pesquisadora, em função da apresentação dos itens de preferência e de dicas e ajudas. Para o terceiro par ensinado, os comportamentos inadequados não apareceram mais.

Tabela 1 - Média da ocorrência dos comportamentos adequados e inadequados nas sessões de linha de base e de intervenção para os quatro participantes

\begin{tabular}{|c|c|c|c|c|c|c|c|c|c|c|c|c|}
\hline & \multicolumn{4}{|c|}{ Repertório 1} & \multicolumn{4}{|c|}{ Repertório 2} & \multicolumn{4}{|c|}{ Repertório 3} \\
\hline & \multicolumn{2}{|c|}{ Linha de base } & \multicolumn{2}{|c|}{ Intervenção } & \multicolumn{2}{|c|}{ Linha de base } & \multicolumn{2}{|c|}{ Intervenção } & \multicolumn{2}{|c|}{ Linha de base } & \multicolumn{2}{|c|}{ Intervenção } \\
\hline & Adeq $^{1}$ & Inad & Adeq & Inad & Adeq & Inad & Adeq & Inad & Adeq & Inad & Adeq & Inad \\
\hline P1 & 1 & 1 & 2,8 & 1 & 2,7 & 0,7 & 3,2 & 0,5 & 2,4 & 0 & 3,9 & 0 \\
\hline P2 & 2 & 0,3 & 3,2 & 1 & 1,7 & 0,7 & 3,2 & 0,5 & 1,6 & 0 & 4,2 & 0 \\
\hline P3 & 0 & 0 & 4,3 & 0,1 & 1 & 0 & 3,7 & 0 & 1,4 & 0 & 3,8 & 0 \\
\hline P4 & 0,3 & 2 & 4 & 0,1 & 0,7 & 0 & 4 & 0 & 1,2 & 0 & 3 & 0 \\
\hline
\end{tabular}

Fonte: Fonte própria.

1 "Adeq" refere-se aos comportamentos adequados e "Inad" refere-se aos comportamentos inadequados. 


\section{Discussão}

De forma geral, pode-se inferir que o procedimento de ensino de habilidades musicais com uso de reforçamento diferencial e esvanecimento de dicas proposta nesta pesquisa foi suficiente para ensinar habilidades rítmicas a quatro meninos com TEA, utilizando instrumentos musicais e cantigas de rodas. Verificou-se também redução a quase zero de comportamentos inadequados e aumento de comportamentos adequados durante as sessões de ensino e teste. Para os Repertórios 1 e 3, os resultados positivos apresentados pelos participantes evidenciam a eficácia dos procedimentos de ensino utilizados. As quatro oportunidades de aprendizagem oferecidas por sessão estabeleceram uma rotina de repetição de tocar os instrumentos musicais. Nesse sentido, o procedimento proposto vai ao encontro das sugestões apresentadas por estudiosos da área da educação musical especial (HAMMEL; HOURIGAN, 2013) e dos pressupostos da intervenção comportamental (MARTIN; PEAR, 2009).

Durante o ensino do primeiro repertório, em que os participantes deveriam tocar de acordo com o pulso musical, eles apresentaram baixa frequência de respostas corretas por algumas sessões até alcançarem o critério de aprendizagem estabelecido. Para o terceiro repertório é possível inferir, com base no menor número de sessões para alcance de critério, que a resposta aprendida para o primeiro repertório (tocar o instrumento de forma contínua, a cada 48 décimos de segundos) deu base para que os participantes tocassem de acordo com o especificado para a terceira cantiga (tocar o instrumento de forma contínua, a cada 36 décimos de segundos para P1, P2 e P3 e a cada 21 décimos de segundos para P4). A literatura ressalta que essa "batida" do pulso musical é realizada sem esforço por seres humanos e que um dos aspectos do comportamento musical é o movimento espontâneo sob controle do pulso e do ritmo da música (REPP; SU, 2013; TRAINOR, 2015). Essa capacidade de perceber batimento ou pulso regular, duração e sequência sonora foi identificada inclusive em bebês recém-nascidos (STEFANICS et al., 2007; WINKLER et al., 2009), sugerindo que tais capacidades se estabelecem no início do desenvolvimento infantil.

Apesar dos resultados positivos para os Repertórios 1 e 3, os participantes mostraram dificuldade para alcançar critério de aprendizagem para o Repertório 2, evidenciado pelo 
http://dx.doi.org/10.5902/1984686X34415

maior número de sessões e pelo fato de somente P1 e P3 alcançarem esse critério. Isso pode ter ocorrido em função da discriminação mais complexa exigida para a cantiga "Sereno". Para os Repertórios 1 e 3, pode-se considerar o início da cantiga como único estímulo discriminativo $\left(\mathrm{S}^{\mathrm{D}}\right)$ para que o participante começasse a tocar o instrumento de uma determinada forma e segue assim até o final da cantiga e um $S^{D}$ final (término da cantiga ou fim do estímulo auditivo) que indicava que o participante deveria parar de tocar o instrumento. Entretanto, para o Repertório 2, a contingência foi diferente, pois o participante deveria iniciar e finalizar o comportamento de tocar o instrumento musical em determinados momentos (em que é cantada a palavra "sereno"). Nesse sentido, no segundo Repertório, vão ocorrer diferentes $S^{D} S$ (por exemplo, a palavra que antecede imediatamente a palavra "sereno") ao longo da cantiga, tornando este repertório mais complexo. Para a cantiga "Sereno", os participantes poderiam ficar, também, sob controle da passagem do tempo, considerando os intervalos entre cada aparição da palavra "sereno", que variavam de uma ocorrência para a próxima.

Uma primeira hipótese sobre a dificuldade encontrada pelos participantes em alcançar critério no Repertório 2 poderia estar relacionada com o fato da palavra "sereno" não fazer parte do repertório verbal deles, por isso, provavelmente não era um estímulo fortemente discriminável ou saliente (COOPER; HERON; HEWARD, 2007). Uma possibilidade para reduzir essa dificuldade, seria apresentar o item de preferência cada vez que o participante tocasse corretamente o instrumento na presença da palavra "sereno". Entretanto, isso dificultaria que o participante respondesse à cantiga inteira em cada tentativa, o que não corresponderia ao objetivo dessa pesquisa. Assim como no estudo de Gallastegi (2005), pode-se inferir que a dificuldade encontrada, principalmente por P2 e P4, possa estar relacionada ao déficit em habilidades perceptivas auditivas e reconhecimento de aspectos relacionados à linguagem, principalmente quando a palavra foco é apresentada junto com uma melodia, o que pode ter dificultado o reconhecimento da palavra "sereno".

Uma segunda hipótese é que os participantes, principalmente P2 e P4, não estabeleceram controle temporal para realizar a atividade, principalmente, em função do reforço ser apresentado somente após o término da cantiga e não no exato momento após os participantes terem tocado o chocalho em cada palavra "sereno". Tal esquema de reforçamento pode não ter sido eficaz para estabelecer o aprendizado, porém, é preciso ressaltar, novamente, que apresentar o reforço a cada resposta correta inviabilizaria a atividade proposta, interrompendo o andamento da cantiga. 
Os resultados das sondas de generalização vão ao encontro da afirmação de Cox (1985) de que as habilidades musicais adquiridas em um processo de musicalização possibilitam a emissão dessas respostas em outros contextos. Nas sondas de generalização, a resposta alvo era que os participantes tocassem os instrumentos musicais aprendidos na presença de determinada cantiga também na presença das outras cantigas, o que ocorreu para os Repertórios 1 e 3. No caso da cantiga "sereno", esperava-se que os participantes tocassem os instrumentos "chocalho" e "clavas" toda a vez em que a palavra "sereno" fosse pronunciada. Porém, o que se verificou é que todos os participantes generalizaram a forma de tocar continuamente, sob controle do instrumento, ou seja, com o instrumento chocalho, eles tocaram o instrumento de forma contínua, a cada 48 décimos de segundos, e com as clavas, eles tocaram de forma contínua a cada 36 décimos de segundos (P1, P2 e P3) ou a cada 21 décimos de segundos (P4).

Os dados apresentados para os Repertórios 1 e 3 (tocar no pulso e na subdivisão, respectivamente) mostram que o comportamento de imitar a resposta da pesquisadora de tocar continuamente determinado instrumento foi de fácil assimilação para todos os participantes transferindo-se, portanto, para todos os repertórios. Esses resultados sugerem a eficácia do uso de imitação e de reforçamento diferencial como uma estratégia de ensino para o aprendizado de novos repertórios (LOVAAS, 1981; MILLER; RODRIGUEZ; ROURKE, 2015). Musicalmente falando, o pulso possui uma importância fundamental na música, pois ele é a base que proporcionará a sincronia com o ritmo musical além de favorecer a coordenação entre percepção musical ou auditiva e ação (LARGE; SNYDER, 2009), o que pode ser operacionalizado como o controle exercido pelo estímulo auditivo da cantiga sobre a resposta motora de tocar o instrumento. Portanto, pode-se inferir que os todos os participantes tiveram um ganho significativo em termos de aprendizagem musical.

Os comportamentos adequados registrados neste estudo tiveram sua frequência aumentada durante as sessões de ensino para todos os participantes. Esses comportamentos são comumente indicados como deficitários nessa população e são necessários em ambiente escolar, como seguir comandos e instruções, responder a perguntas, aceitar ajudas que impliquem em contato físico, atentar para os materiais e fazer contato visual, e em ambiente social, como cumprimentar e despedir-se. Estes resultados corroboram aqueles encontrados por Alves, Vieira e Serrano (2010), que observaram o 
http://dx.doi.org/10.5902/1984686X34415

aumento de comportamentos adequados após intervenções musicais com três crianças com TEA.

Somente a título de exemplificação, as análises dos vídeos mostram que P1 manteve sorriso no rosto em aproximadamente $90 \%$ das sessões. Esta é uma informação relevante, pois, segundo a professora da instituição, P1 não apresentava tal comportamento em sala de aula, indicando, possivelmente, que as atividades musicais e/ou a pesquisadora tornaram-se reforçadores para P1. Esse comportamento de P1 confirma o que a literatura sobre educação musical diz sobre os benefícios da música. Ela pode promover e desenvolver diferentes emoções, como a felicidade, a sociabilidade e a sensibilidade (HAMMEL; HOURIGAN, 2013; JOLY; ALLIPRANDINI; ASNIS, 2008).

Outro fator que pode inferir o valor reforçador do contexto em que essa pesquisa foi conduzida é a diminuição dos comportamentos inadequados apresentada, de maneira geral, por todos os participantes. Ressalta-se, ainda, que a utilização de um ensino por tentativas discretas (DTT, do inglês Discrete Trial Teaching) pode ter contribuído para a diminuição de comportamentos inadequados dos quatro participantes, corroborando com resultados encontrados em outros estudos (DIB; STURMEY, 2007; KOEGEL; RUSSO; RINCOVER, 1977; SAROKOFF; STURMEY, 2004). Essa diminuição pode ter sido função do acesso constante aos reforçadores, comum em sessões de ensino que utilizam o DTT, pois a privação desses estímulos pode gerar uma operação estabelecedora para a emissão de comportamentos inadequados, quando os adequados não os produzem de forma consistente.

Estudos futuros poderiam verificar a generalização dos repertórios observados nessa pesquisa, tanto os musicais quanto os comportamentos adequados, para outros ambientes e na presença de outras pessoas. Uma das limitações deste estudo foi a não realização de uma avaliação de repertório verbal dos participantes e uma avaliação itens de preferência pré-experimento, procedimentos estes considerados importantes para a obtenção de resultados mais eficazes, portanto, sugere-se que para novos estudos estes procedimentos sejam realizados. A limitação de bibliografia que contemplasse o ensino de habilidades musicais para pessoas com TEA utilizando intervenção comportamental, excluindo-se pesquisas sobre musicoterapia, restringiu a discussão deste trabalho.

Finalmente, vale ressaltar que a musicalização contempla uma gama de atividades que contribuem para a formação integral da criança, entretanto, esta pesquisa se propôs 
http://dx.doi.org/10.5902/1984686X34415

estudar apenas um recorte deste grande tema, oportunizando aos participantes, um contato inicial com a linguagem musical de forma estruturada e adaptada às características deles.

\section{Referências}

ALVES, Iraí Cristina Boccato; DUARTE, José Luciano Miranda. Escala de Maturidade Mental Columbia, São Paulo: Casa do Psicólogo, 2001.

ALVES, Nelson; VIEIRA, Maria Helena; SERRANO, Ana Maria. Educação Musical na Intervenção Precoce. Inclusão, v. 10, p. 29-38, 2010.

AMERICAN PSYCHIATRIC ASSOCIATION. APA. (2014). Diagnostic and Statistical Manual of Mental Disorders: DSM-5, tradução: Maria Inês Corrêa Nascimento...et al.; revisão técnica: Aristides Volpato Cordioli...[et al.]. - Porto Alegre: Artmed, 2014.

BAILEY, Jennifer Anne; ZATORRE, Robert J.; PENHUNE, Virginia B. Early Musical Training Is Linked to Gray Matter Structure in the Ventral Premotor Cortex and Auditory - Motor Rhythm Synchronization Performance? Journal of Cognitive Neuroscience, v. 26, n. 4, p. 755-767, 2014.

COOPER, John O.; HERON, Timothy E.; HEWARD, William L. Applied behavior analysis. (2nd ed.). Upper Saddle River, NJ: Pearson, 2007.

COX, Dennis K. Suzuki, Chorally Speaking. Music Educators Journal, v. 71, n. 9, p. 4345, 1985.

COZBY, Paul C. Métodos de pesquisa em ciência do comportamento. São Paulo: Atlas, 2014.

DIB, Nancy; STURMEY, Peter. Reducing student stereotypy by improving teachers' implementation of discrete-trial teaching. Journal of Applied Behavior Analysis, v. 40, n. 2, p. 339-343, 2007.

GALLASTEGI, José Ramón Vitoria. Desarrollo de aptitudes perceptivas auditivas en personas con necesidades educativas especiales. Revista Eletrónica de LEEME, v. 16, p. 105-111, 2005.

HAMMEL, Alice M.; HOURIGAN, Ryan M. Teaching Music to Students with Autism. Oxford University Press, 2013.

ILARI, Beatriz Senoy. Bebês também entendem de música: a percepção e a cognição musical no primeiro ano de vida. Revista da ABEM, v.10, n. 7, p. 83-90, 2002.

JOLY, Ilza Zenker Leme; ALLIPRANDINI, Silvia Falco; ASNIS, Valéria Peres. Práticas pedagógicas e musicais na comunidade: uma experiência em um hospital. In: XVII Encontro Nacional da ABEM, São Paulo. Diversidade Musical e Compromisso Social: O papel da Educação Musical. São Paulo: Editora UNESP, v. 1. p. 1-6, 2008. 
KLEBER, Boris; VEIT, Ralf; BIRBAUMER, Niels; GRUZELIER, John; LOTZE, Martin. The brain of opera singers: experience-dependent changes in functional activation. Cerebral Cortex, v. 20, n. 5, p. 1144-1152, 2010.

KOEGEL, Robert L.; RUSSO, Dennis C.; RINCOVER, Arnold. Assessing and training teachers in the generalized use of behavior modification with autistic children. Journal of Applied Behavior Analysis, v. 10, n. 2, p. 197-205, 1977.

LANOVAZ, Marc J.; SLADECZEK, Ingrid E.; RAPP, John T. Effects of music on vocal stereotypy in children with autism. Journal of Applied Behavior Analysis, v. 44, n. 3, p. 647-651, 2011.

LANOVAZ, Marc J.; RAPP, John. T.; FERGUSON, Stéphanie. The utility of assessing musical preference before implementation of noncontingent music to reduce vocal stereotypy. Journal of Applied Behavior Analysis, v. 45, n. 4, p. 845-851, 2012.

LARGE, Edward W.; SNYDER, Joel S. Pulse and Meter as Neural Resonance. Annals of the New York Academy of Sciences, v. 1169, p. 46-57, 2009.

LOURO, Viviane. Educação Musical e Deficiência: propostas pedagógicas. São José dos Campos, SP: Ed. Do Autor, 2006.

LOVAAS, Ole Ivar. Teaching developmentally disabled children. Baltimore, Maryland: University Park Press, 1981.

MARTIN, Garry; PEAR, Joseph. Modificação de comportamento: o que é e como fazer. [tradução Noreen Campbell de Aguirre; revisão científica Hélio José Guilhardi]. - 8.ed. - São Paulo: Roca, 2009.

MARTIN, L. K. Applied Behaviour Analysis: Introduction and Practical Application in Music Therapy for Young Children with Autism Spectrum Disorders. In: Kern, P.; Humpal, M. (Eds.). Early childhood therapy and autism spectrum disorders: Developing potential in young children and their families. Philadelphia, PA: Jessica Kingsley Publishers, 2013.

MILLER, Scott A.; RODRIGUEZ, Nicole M.; ROURKE, Ami J. Do mirrors facilitate acquisition of motor imitation in children diagnosed with autism? Journal of Applied Behavior Analysis, v. 48, n. 1, p. 1-5, 2015.

ORGANIZAÇÃO MUNDIAL DA SAÚDE, OMS, CID 10 - Classificação De Transtornos Mentais e de Comportamento: Descrições Clínicas e Diretrizes Diagnósticas. Porto Alegre: Artmed, 1993.

PIMENTEL, Altimar de Alencar. Esquindô-lê-lê: cantigas de roda. João Pessoa: Editora Universitária/UFPB, 2002.

REPP, Bruno H.; SU, Yi-Huang. Sensorimotor synchronization: a review of recent research (2006- 2012). Psychonomic Bulletin \& Review, v. 20, n. 3, p. 403-452, 2013.

SAROKOFF, Randi A.; STURMEY, Peter. The effects of behavioral skills training on staff implementation of discrete-trial teaching. Journal of Applied Behavior Analysis, v. 37, n. 4, p. 535-538, 2004. 
SAYLOR, Sharyn; SIDENER, Tina M.; REEVE, Sharon A.; FETHERSTON, Anne; PROGAR, Patrick R. Effects of three types of noncontingent auditory stimulation on vocal stereotypy in children with autism. Journal of Applied Behavior Analysis, v. 45, n. 1, p. 185-190, 2012.

SCHOPLER, Erik; REICHLER, Robert J.; RENNER, Barbara Rochen. The Childhood Autism Rating Scale (CARS), Los Angeles, Ca: Western Psychological Services, 1988.

SILVA, Elaine de Carvalho; ELIAS, Nassim Chamel. Ensino de Relações Espaciais de Esquerda e Direita a Participantes com Autismo e Deficiência Intelectual. Psicologia: Teoria e Pesquisa, v. 33, p. 1-8, 2017.

SRINIVASAN, Sudha M.; BHAT, Anjana N. A review of "music and movement" therapies for children with autism: embodied interventions for multisystem development. Frontiers Integrative Neuroscience, v. 7, n. 22, p. 1-15, 2013.

STEELE, Christopher J.; BAILEY, Jennifer A.; ZATORRE, Robert J.; PENHUNE, Virginia B. Early musical training and white-matter plasticity in the corpus callosum: evidence for a sensitive period. The Journal of Neuroscience, v. 33, n. 3, p. 1282-1290, 2013.

STEFANICS, Gábor; HÁDEN, Gábor; HUOTILAINEN, Minna; BALÁZS, László; SZILLER, István; BEKE, Anna; FELLMAN, Vineta; WINKLER, István. Auditory temporal grouping in newborn infants. Psychophysiology, v. 44, n. 5, p. 697-702, 2007.

TRAINOR, Laurel J. The origins of music in auditory scene analysis and the roles of evolution and culture in musical creation. Philosophical Transactions of the Royal Society B, v. 370, n. 1664, p. 1-14, 2015

WINKLER, István; HÁDEN, Gábor P.; LADINIG, Olivia; SZILLER, István; HONING, Henkjan. Newborn infants detect the beat in music. Proceedings of the National Academy of Sciences of the United States of America, v. 106, n. 7, p. 2468-2471, 2009.

\section{Agradecimentos}

Os autores agradecem à CAPES pela bolsa de doutorado para a primeira autora e pela bolsa de pós-doutorado para a segunda autora. O presente trabalho foi realizado com apoio da Coordenação de Aperfeiçoamento de Pessoal de Nível Superior - Brasil (CAPES) - CAPES/PROEX № do Processo: 23038.005155/2017-67. Esse trabalho é derivado da tese de doutorado da primeira autora.

\section{Correspondência}

Valéria Peres Asnis - Universidade Federal de São Carlos. Rod. Washington Luiz, s/n, São Carlos. CEP: 13565-905. São Carlos, São Paulo, Brasil.

http://orcid.org/0000-0002-1825-0097 


\section{(c) $($ ) (i) $(9)$}

This work is licensed under a Creative Commons Attribution-NonCommercial 4.0 International (CC BY-NC 4.0) 